\title{
Expression of HLA-DR antigens on bile duct epithelium in primary sclerosing cholangitis
}

\author{
R W CHAPMAN, P M A KELLY, A HERYET, D P JEWELL, \\ AND K A FLEMING \\ From the Departments of Gastroenterology and Nuffield Department of Pathology, (University of Oxford), \\ John Radcliffe Hospital, Oxford
}

SUMmaRY The expression of HLA class I (HLA-A, B, C) and class II (HLA-DR) antigens on the biliary epithelium of 10 patients (nine men) with primary sclerosing cholangitis (PSC) was investigated using an immunoperoxidase technique on cryostat sections. Five patients were staged as grade II and five grade III on hepatic histology. None were cirrhotic. Controls were nine patients with primary biliary cirrhosis (PBC), five with extra hepatic biliary obstruction, 15 with other forms of chronic liver disease and six with normal livers. Bile ducts from the normal subjects and patients with chronic liver disease did not express HLA-DR antigens. In contrast, all 10 of the PSC biopsies showed varying degrees of HLA-DR staining of the biliary epithelium. Expression of DR antigens was also found on the bile ducts of all five patients with extra hepatic biliary obstruction and in six of nine patients with PBC. Expression of HLA class I antigens was seen on the biliary epithelium of all the biopsies examined. Increased numbers of helper and suppressor $T$-cells were seen in the portal tracts of all the PSC patients. This study has confirmed that aberrant expression of HLA-DR may occur on the biliary epithelium of some, but not all, patients with PBC. In addition, the study has shown that aberrant expression of HLA-DR always occurs in PCS at an early stage of histological liver damage. While this may be important in the pathogenesis of PSC, the aberrant expression in extra hepatic biliary obstruction suggests that it may be a secondary phenomenon.

Primary sclerosing cholangitis (PSC) is an uncommon disease characterised by chronic inflammatory fibrosis usually affecting the entire biliary tree, causing beading and stricturing of the bile ducts. ${ }^{1}$ The aetiology of PSC is unknown. It has been suggested recently, however, that genetic and immunological factors are important in the pathogenesis of PSC. There is a close relationship between the human leucocyte antigen (HLA) B8 DR3 phenotype and PSC. ${ }^{23}$ This phenotype is closely associated with a number of organ specific autoimmune diseases, such as 'lupoid' chronic active hepatitis, type I diabetes mellitis, myasthenia gravis, and thyrotoxicosis. ${ }^{4}$ In addition, other studies have shown humoral and cellular immune abnormalities in

Address for correspondence: Dr R W Chapman, BSc, MD, MRCP, Department of Gastroenterology, John Radcliffe Hospital, Headington, Oxford OX3 9DU.

Received for publication 9 October 1987.
PSC, $5-7$ drawing parallels with autoimmune processes.

The class II major histocompatibility complex (MHC) antigens (HLA-DR) are glycoproteins on the cell surface which play an important role in presenting antigens and thus regulating the immune response. Expression of HLA-DR antigens is normally restricted to macrophages, ${ }^{8}$ Blymphocytes, ${ }^{910}$ vascular endothelial, "dendritic and other antigen presenting cells and certain epithelial cells. Recent studies have shown, however, that in organ specific autoimmune states normally negative epithelial cells in the target organ express HLA-DR for example, in autoimmune thyroiditis. ${ }^{12}$ In addition, expression of HLA-DR antigens has been shown on bile duct epithelium in primary biliary cirrhosis. ${ }^{13}$

In view of these similarities between PSC and other organ specific autoimmune diseases, the aim of this 
Table 1 Clinical, biochemical, and histological details of 10 patients with primary sclerosing cholangitis (PSC)

\begin{tabular}{|c|c|c|c|c|c|c|c|c|c|c|}
\hline Patient no & 1 & 2 & 3 & 4 & 5 & 6 & 7 & 8 & 9 & 10 \\
\hline Symptoms & No & No & Pruritus & Pruritus & Malaise & Malaise & No & No & Pruritus & No \\
\hline Sex/age $(\mathrm{yr})$ & F69 & M57 & M43 & M74 & M35 & M64 & M42 & M28 & M22 & M59 \\
\hline Distribution of UC & No UC & L sided & Total & Total & L sided & Total & Total & Total & Total & Total \\
\hline Extent of bile duct changes on ERCP & $\mathrm{IH}$ & IH & $\mathrm{IH}+\mathrm{EH}$ & $\mathrm{IN}+\mathrm{EH}$ & $\mathrm{IH}+\mathrm{EH}$ & $\mathrm{IH}$ & IH & IH & IH & IH \\
\hline Asparate transaminase $(3-35$ IU $/ 1)$ & 48 & 92 & 90 & 108 & 27 & 187 & 30 & 41 & 170 & 142 \\
\hline Alkaline-phosophatase (75-300 IU/l) & 659 & 559 & 1205 & 2403 & 836 & 431 & 852 & 691 & 1554 & 1134 \\
\hline Bilirubin $(0-17 \mathrm{mmol} / \mathrm{l})$ & 9 & 16 & 1 & 108 & 14 & 11 & 6 & 14 & 7 & 33 \\
\hline Albumin $(35-50 \mathrm{~g} / \mathrm{l})$ & 42 & 44 & 47 & 33 & 40 & 40 & 47 & 49 & 35 & 35 \\
\hline Liver biopsy Stage I-IV & II & II & III & III & III & II & II & II & III & III \\
\hline
\end{tabular}

$\mathrm{IH}=$ Intrahepatic; $\mathrm{EH}=$ extrahepatic; $\mathrm{UC}=$ ulcerative colitis; normal ranges of investigations are shown in brackets; liver biopsies were staged according to Ludwig et al. $^{14}$

The conversion factors from S1 units to traditional units are as follows: (1) Alkaline phosphatase: $\div$ S1 unit $\times 23$ to convert to King Armstrong Units/dl; (2) Albumin:

$\div$ S1 unit $\times 10$ to convert to $\mathrm{g} / \mathrm{dl} ;(3)$ Bilirubin: $+\mathrm{S} 1$ unit $\times 17$ to conver to $\mathrm{mg} / \mathrm{dl}$.

study was to investigate the expression of HLA-ABC and HLA-DR on bile duct epithelium in liver biopsy specimens obtained from patients with PSC and other chronic liver diseases, including PBC and large bile duct obstruction.

\section{Methods}

\section{PATIENTS}

Ten patients with PSC were studied (nine men). The diagnosis was established on the basis of accepted clinical, histological, and cholangiographic criteria. ${ }^{1}$ The clinical features and laboratory findings are shown in Table 1 . Nine of the 10 patients also suffered from ulcerative colitis. Five patients were staged as grade II and 5 grade III using hepatic histological criteria. ${ }^{14}$ None were cirrhotic. No patients with PSC had circulating antimitochondrial antibody. Patients 5 and 10 had significant titres of antinuclear factor, one in 160 and one in 80 respectively. In addition, nine patients with PBC were studied (eight women). Liver biopsy specimens were also obtained from five patients with large bile duct obstruction, 12 patients with alcoholic liver disease of varying severity, three patients with autoimmune chronic active hepatitis, and six subjects with mildly abnormal liver function tests but with histologically normal liver biopsies.

\section{LIVER BIOPSY SPECIMENS}

These were obtained percutaneously with a $1.6 \mathrm{~mm}$ Menghini needle. Samples were immediately divided in half. One portion was fixed in formalin and embedded in paraffin for histological examination. The second half was embedded in Tissue Tek OCT medium immediately after the biopsy was obtained, snap frozen in 2-methyl butane, precooled in liquid nitrogen, and stored in liquid nitrogen. Cryostat sections (5-6 $\mu$ thick) were air dried for two hours at $20^{\circ} \mathrm{C}$, fixed in acetone at $-20^{\circ} \mathrm{C}$ for 15 minutes and then air dried at $20^{\circ} \mathrm{C}$. The sections were either stained immediately or stored at $-20^{\circ} \mathrm{C}$.

\section{IMMUNOCYTOCHEMISTRY}

The HLA-DR antigens were localised using the monoclonal antibody CR3/43 by means of the three stage indirect immunoperoxidase method. ${ }^{15}$ Other antigens were localised using standard indirect immunoperoxidase methods. ${ }^{16}$ The monoclonal antibodies are listed in the Table 2.

THREE-STAGE IMMUNOPEROXIDASE TECHNIQUE Fixed cryostat sections of liver were incubated with the relevant dilution of monoclonal antibody for 30 minutes, washed in Tris buffered saline (TBS), $\mathrm{pH}$ 7.6 for five minutes and incubated with rabbit antimouse IgG, diluted 1:50 in TBS containing $30 \%$ normal human serum (v/v). Sections were washed in TBS and antirabbit IgG - peroxidase conjugate applied. The conjugate had been previously diluted 1:100 in TBS containing 30\% normal human serum

Table 2 Monoclonal antibodies used for immunoperoxidase staining

\begin{tabular}{|c|c|c|c|c|}
\hline \multicolumn{2}{|c|}{ Antibody Specificity } & \multirow{3}{*}{$\begin{array}{l}\text { Soutce } \\
\text { P. Beverley* } \\
\text { Dako }\end{array}$} & \multirow{3}{*}{$\begin{array}{l}\text { Method } \\
\text { Indirect } \\
\text { Indirect }\end{array}$} & \multirow{3}{*}{$\begin{array}{l}\text { Dilution } \\
1 / 10 \\
\text { Neat }\end{array}$} \\
\hline T28 & Pan-T lymphocyte & & & \\
\hline T310 & $\begin{array}{l}\text { Thelper/inducer } \\
\text { cells }\end{array}$ & & & \\
\hline TU102 & $\begin{array}{l}\text { T cytotoxic/ } \\
\text { suppressor }\end{array}$ & Dako & Indirect & Neat \\
\hline 4KB128 & Pan-B lymphocytes & Dako & Three stage & Neat \\
\hline W6/32 & HLA class I & D Mason $\dagger$ & Indirect & Neat \\
\hline $4 / 23$ & $\begin{array}{l}\text { Follicular dendritic } \\
\text { cells }\end{array}$ & Dako & Three stage & Neat \\
\hline EBM/11 & $\begin{array}{l}\text { Monocytes/ } \\
\text { macrophage }\end{array}$ & Dako & Three stage & Neat \\
\hline $3 / 43$ & HLA class II & D Mason† & Three stage & Neat \\
\hline
\end{tabular}

${ }^{*}$ P Beverley - ICRF Tumour Immunology Unit, University College Hospital, London; †D Mason- John Radcliffe Hospital, Oxford. 
Table 3 Distribution of $H L A-D R$ antigens in biliary and hepatocellular liver disease

\begin{tabular}{|c|c|c|c|c|c|}
\hline Disease & Patients ( $n$ ) & $\begin{array}{l}\text { Focal staining of bile } \\
\text { duct epithelium }\end{array}$ & $\begin{array}{l}\text { Excess lymphocytes } \\
\text { in portal tracts }\end{array}$ & $\begin{array}{l}\text { Diffuse staining of } \\
\text { bile duct epithelium }\end{array}$ & $\begin{array}{l}\text { Hepatocyte } \\
\text { staining }\end{array}$ \\
\hline Primary sclerosing cholangitis & 10 & 3 & ++ & 7 & 0 \\
\hline Primary biliary cirrhosis & 9 & 3 & ++ & 3 & 0 \\
\hline Normal controls & 6 & 0 & 0 & 0 & 0 \\
\hline Chronic liver disease & 15 & 0 & + & 0 & 0 \\
\hline Extra-hepatic bile duct obstruction & 5 & 1 & + & 4 & 0 \\
\hline
\end{tabular}

$(\mathrm{v} / \mathrm{v})$. Peroxidase was demonstrated by immersing washed sections for 10 minutes in 3.3 diaminobenzidine tetrachloride (BDH) $(0.8 \mathrm{mg} / \mathrm{ml})$, containing $\mathrm{H}_{2} \mathrm{O}_{2}(0.08 \% \mathrm{v} / \mathrm{v})$ in TBS, washed in tap water and counterstained with haematoxylin. As a negative antibody control, sections were incubated with the second and third antibody only.

IN DIRECT IMMUNOPEROXIDASE TECHNIQUE Fixed cryostat sections were incubated with the relevant monoclonal antibody (Table 2) for one

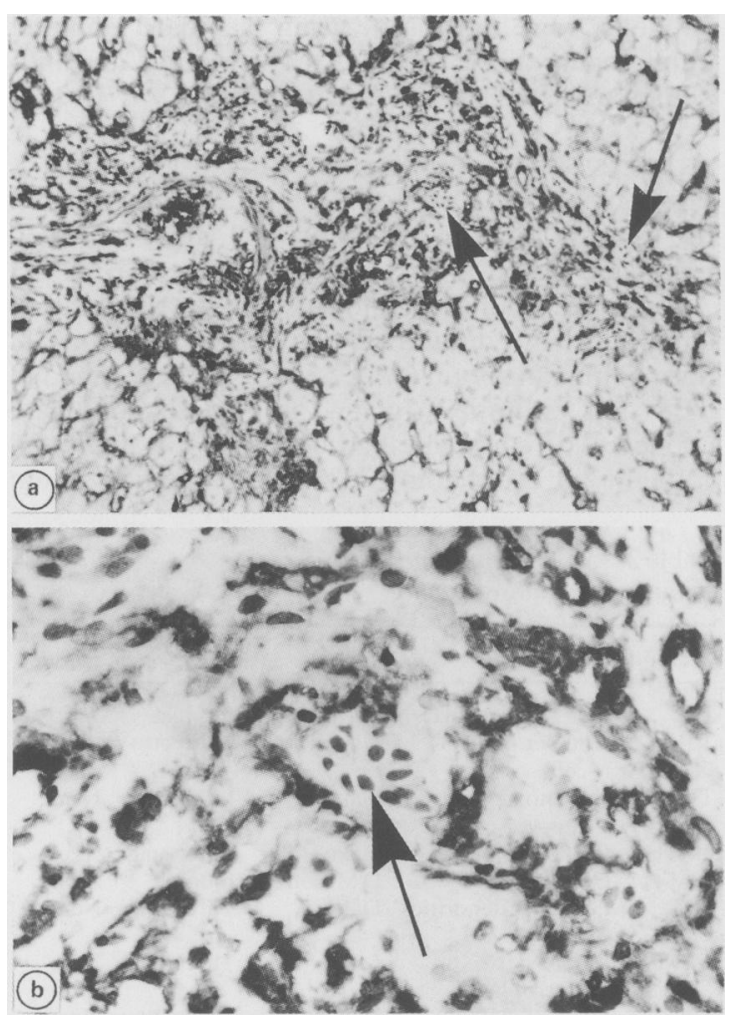

Fig. 1 Acute alcoholic hepatitis with fibrosis and inflammation in portal tracts. Epithelium of the bile ducts is negative for HLA-DR (arrows); inflammatory and Küpffer cells are positive. Antibody 3/43. hour, in TBS for five minutes and rabbit antimouse IgG conjugated with peroxidase (Dakopatts) for 30 minutes as described above. After a five minute wash in TBS, peroxidase was demonstrated as in the three stage immunoperoxidase technique.

EXAMINATION OF THE STAINED SECTIONS Stained sections were read by a histopathologist (KF) who was unaware of the patients' diagnoses.

\section{Results}

In all patients studied, HLA class I antigens were expressed on the biliary epithelium and sinusoidal lining cells.

The results of the HLA-DR expression on bile ducts in the various conditions are shown in Table 3. In the alcoholic patients, patients with chronic active hepatitis and normal controls, the bile ducts and hepatocytes were negative for expression of HLADR (Figs 1a, b). Although DR - positive cells were sometimes observed near to the basement membrane of bile ducts, these cells had the features of infiltrating macrophages, being positive with EBM/11.

In PSC specimens strong staining of biliary epithelium was observed in every case (Figs 2 and 3). In seven of the 10 patients, expression of HLA-DR was found on every bile duct examined in the section, although not involving every cell. In three patients expression was more focal, not occurring in every portal tract. There was no relationship between the severity of symptoms or the histological stage of the liver disease in the PSC group and the focality or intensity of the staining. Similarly, all five patients with extra hepatic bile duct obstruction exhibited HLA-DR staining (Fig. 4). In four of five biopsies strong straining was observed, involving every bile duct, whilst in one, more focal involvement was seen.

In the sections from the PBC patients, HLA-DR was expressed on bile duct epithelium in six of nine biopsies. The pattern of staining was focal in three, with the bile ducts in some portal tracts expressing HLA-DR, whilst other portal tracts were completely negative for HLA-DR staining. The intensity of staining was also less in the PBC group compared with PSC. There was no relationship between the 


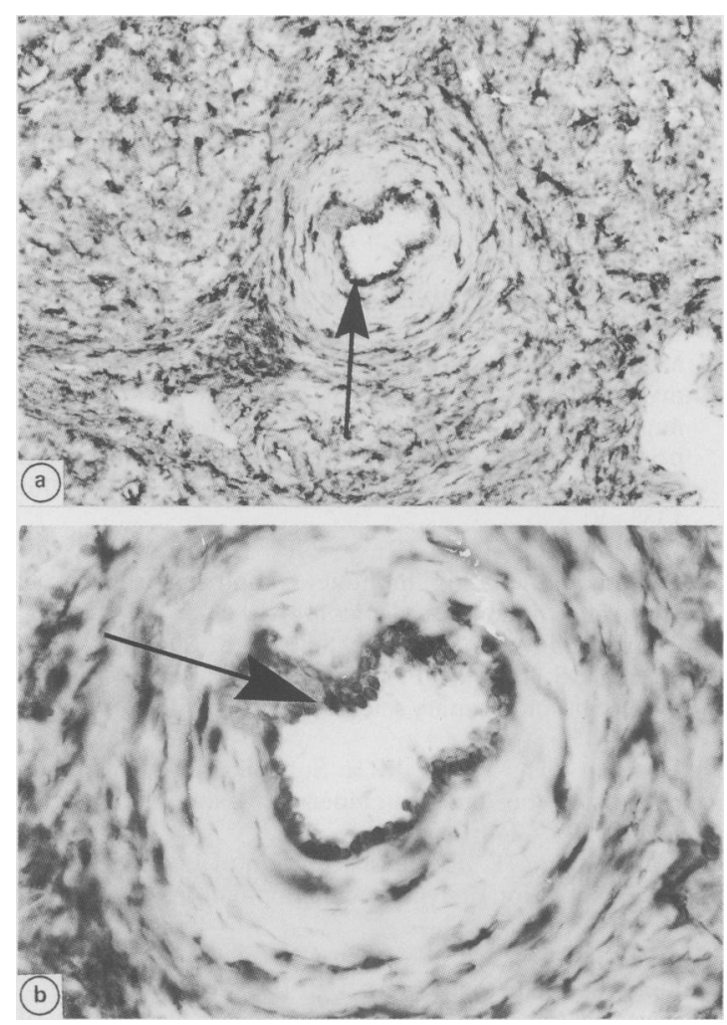

Fig. 2 Portal tract in primary sclerosing cholangitis showing HLA-DR expression of varying intensity on the biliary epithelium (arrow). Antibody 3/43.

focality of the bile duct staining and the stage of PBC.

Portal tracts from patients with PBC and PSC examined in haematoxylin and eosin stained sections contained increased numbers of lymphocytes, macrophages, and plasma cells. T lymphocytes subsets were examined semiquantitively in both groups of patients. In the majority of those patients with PSC and patients with primary biliary cirrhosis, T helper inducer cells predominated in the portal tracts, although relatively increased numbers of T cytotoxicsuppressors were also observed. Further details of the quantitation of the T cell subtypes in liver sections compared with peripheral blood will be published elsewhere.

\section{Discussion}

The major histocompatibility class II (DR) antigens are important modulators of the immune response. ${ }^{17}$ Thus the expression of HLA-DR antigens on the surface membrane of the cell enables the cell to present antigens to $\mathrm{T}$ lymphocytes, which may, as a

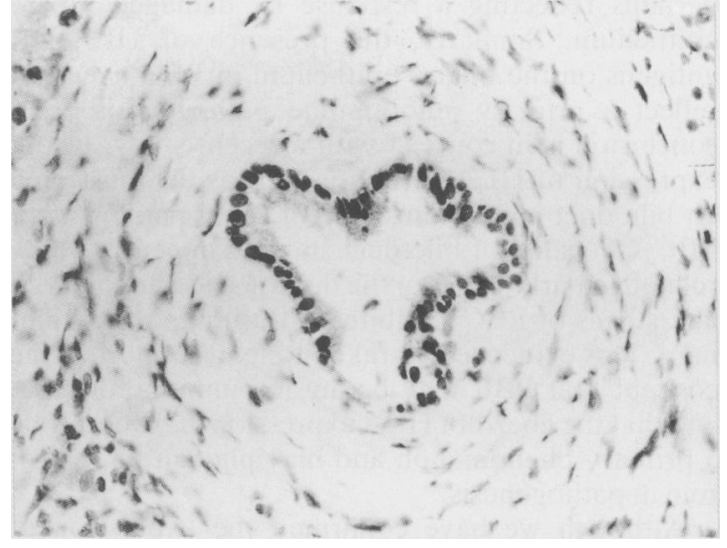

Fig. 3 Negative antibody control of same portal tract as Figure 2.

result, undergo activation and differentiation. These activated T-cells may play an important role in immune response regulation. Because studies in organ specific autoimmune states have shown that epithelial cells in the target organ express HLA-DR, it has been suggested that the aberrant expression of HLA-DR on the target cells may play an important role in the pathogenesis of these diseases. ${ }^{18}$

Accordingly the presence of HLA-DR on the biliary epithelium of all 10 cases of PSC examined might support the proposed autoimmune nature of this disease. ${ }^{19}$ The presence of HLA-DR expression in all 5 cases of large duct obstruction examined, where there is no primary pathogenetic role for autoimmune mechanisms, could suggest, however, that HLA-DR expression is a secondary event,

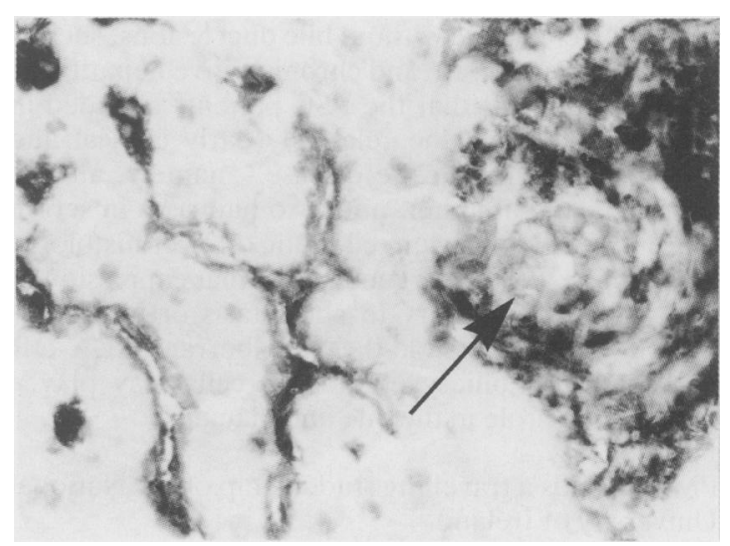

Fig. 4 Portal tract in extra hepatic biliary obstruction. Biliary epithelium is positive for $H L A-D R$ (arrow). Antibody 3/43. 
perhaps reflecting a response by damaged biliary epithelium. Similarly, the presence of HLA-DR antigens on the biliary epithelium in PBC need not reflect a primary autoimmune pathogenesis. This conclusion is in contrast with a recent study, where expression of HLA-DR antigens was demonstrated on bile duct epithelium in eight of 10 patients with PBC. ${ }^{13}$ Focality of bile duct staining appeared to be related to early stages of the disease and patients with late stages of PBC exhibited diffuse bile duct staining. ${ }^{13}$ This evidence was taken to lend support to the concept that $\mathrm{PBC}$ may be an autoimmune disease, and that the aberrant HLA expression in PBC may be a primary phenomenon and may play an important role in pathogenesis. ${ }^{13}$

Although we have confirmed the expression of HLA-DR antigens in PBC, as in PBC, we have been unable to confirm the relationship between the focaility of bile duct staining and the stage of the disease. Furthermore in contrast with our study, the original study of Ballardini and coworkers included few cholestatic controls, and in particular no patients with extra hepatic bile duct obstruction or PSC were studied. ${ }^{13}$ As our study has shown that the expression of HLA-DR may often occur in cholestatic liver disease of different aetiologies, the expression of HLA-DR antigens on biliary epithelium in PBC may, like PSC, represent a secondary phenomenon associated with either cholestasis or inflammation. Support for this interpretation is provided by a recent report from Van den Oord et al. ${ }^{20}$ These workers found that while 24/26 PBC patients expressed HLA-DR on biliary epithelium, aberrant expression was also found in 10 patients with acute and chronic cholangitis, two cases of PSC and 10 cases of chronic aggressive hepatitis with bile duct lesions.

It is noteworthy, however, that both in our and the earlier studies, ${ }^{1420}$ HLA-DR was not expressed in chronic liver disease without bile duct lesions, such as alcoholic liver disease and chronic active hepatitis. It is also of interest that the PSC patients included in our study were in the relatively early clinical and histological stages of the disease - namely, all had normal serum albumin, only two had rises in serum bilirubin, and none were cirrhotic on liver histology. Thus, while we have argued above that expression of HLA-DR is secondary to cholestasis or inflammation, it remains possible that the aberrant HLA-DR expression on biliary epithelium cells may play a pathogenetic role in the bile duct damage.

PMAK holds a travelling studentship of the National University of Ireland.

\section{References}

1 Chapman RW, Arborgh BAM, Rhodes JM, et al.
Primary sclerosing cholangitis - a review of its clinical features, cholangiography and hepatic histology. Gut 1980; 21 : 870-7.

2 Chapman RW, Varghese Z, Gaul R, Kokkinon N, Sherlock S. Association of primary sclerosing cholangitis with HLA-B8. Gut 1983; 24: 38-41.

3 Shepherd HA, Selby WS, Chapman RWG, et al. Ulcerative colitis and liver dysfunction. $Q J$ Med 1983; 52: 503-13.

4 Eddleston ALWF, Williams R. HLA and liver disease. Br Med Bull 1978; 34: 295-300.

5 McFarlane IG, Wojcicka BM, Tsantoulas DC, Portmann BC, Eddleston ALWF, Williams R. Leukocyte migration inhibition in response to biliary antigens in primary biliary cirrhosis, sclerosing cholangitis, and other chronic liver diseases. Gastroenterology 1979; 76: 1333-40.

6 Bodenheimer HC, LaRusso NF, Thayer WR, et al. Elevated circulating immune complexes in primary sclerosing cholangitis. Hepatology 1983; 3: 150-4.

7 Chapman RW, Cottone M, Selby WS, Shepherd HA, Sherlock S, Jewell DP. Serum autoantibodies, ulcerative colitis and primary sclerosing cholangitis. Gut 1986; 27: 86-91.

8 Rowden GT, Lewis MG, Sulivan AK. Ia antigen expression on human epidermal Langerhan's cells. Nature 1977; 268: 247-8.

9 Hammeling GT. Tissue distribution of Ia antigens and their expression on lymphocyte populations. Transplant Rev 1976; 30: 64-82.

10 Fu SM, Chiorazzi N, Wang CY, et al. Ia bearing Tlymphocytes in man. $J$ Exp Med 1978; 148: 1423-8.

11 Gatter KC, Abdulaziz Z, Beverley P, et al. Use of monoclonal antibodies for the histopathological diagnosis of human malignancy. J Clin Pathol 1982; 35: 1263-7.

12 Hanafusa T, Pujol-Barrell R, Chiovato R, Russell RCG, Domiach D, Bottazzo GF. Aberant expression of HLA-DR antigen on thyrocytes in Graves disease: relevance for auto-immunity. Lancet 1983; ii: 1111-5.

13 Ballardini G, Mirakian R, Bianchi FB, Pisi E, Doniach D, Bottazzo GF. Aberrant expression of HLA-DR antigens on bile duct epithelium in primary biliary cirrhosis: relevance to pathogenesis. Lancet 1987; ii: 1009-12.

14 Ludwig J, Barham SS, LaRusso NF, Elveback LR, Wiesner RH, McCall JT. Morphologic features of chronic hepatitis associated with primary sclerosing cholangitis. Hepatology 1981; 1: 632-40.

15 Gatter KC, Balini B, Mason DY. The use of monoclonal antibodies. In: Anthony PD, MacSween RNWW, eds. Histopathological diagnosis in recent advances in histopathology 12. Edinburgh: Churchill Livingstone: 1984.

16 Barbatis C, Kelly P, Greveson J, Heryet A, McGee J. O'D. Immunocytochemical analysis of HLA class II (DR) antigens in human liver disease. J Clin Pathol 1987; (Submitted).

17 Anonymous. Significance of self recognition and interleukin 2 for immunoregulation, autoimmunity and cancer. [Editorial] Scand J Immunol 1982; 16: 26978. 
18 Botazzo GF, Pujol-Borrell R, Hanafusa T, Feldman M. Role of aberrant HLA-DR expression and antigen presentation in induction of endocrine autoimmunity. Lancet 1983; ii: 1115-9.

19 Chapman RW, Jewell DP. Primary sclerosing cholangitis - an immunologically mediated disease? West J Med 1985; 143: 193-5.

20 Van den Oord JJ, Sciot R, Desmet VJ. Expression of MHC products by normal and abnormal bile duct epithelium. J Hepatol 1986; 3: 310-7. 